\title{
Aspectos ambientais e genéticos de características reprodutivas e produtiva em cabras leiteiras utilizando amostragem de Gibbs
}

\author{
Environmental and genetic aspects of reproductive and productive traits in dairy goats \\ using Gibbs sampling
}

\author{
SANTOS, Natanael Pereira da Silva ${ }^{1 *}$; SARMENTO, José Lindenberg Rocha ${ }^{2}$; \\ PIMENTA FILHO, Edgard Cavalcanti ${ }^{3}$; CAMPELO, José Elivalto Guimarães ${ }^{4}$; \\ FIGUEIREDO FILHO, Luiz Antonio Silva ${ }^{1}$; SOUSA JÚNIOR, Severino Cavalcante \\ $\mathrm{de}^{2}$; REGO NETO, Aurino de Araújo ${ }^{1}$ Ó, Alan Oliveira do ${ }^{1}$
}

\footnotetext{
${ }^{1}$ Universidade Federal do Piauí, Centro de Ciências Agrárias, Programa de Pós-Graduação em Ciência Animal, Teresina, Piauí, Brasil.

${ }^{2}$ Universidade Federal do Piauí, Campus Cinobelina Elvas, Departamento de Zootecnia, Bom Jesus, Piauí, Brasil.

${ }^{3}$ Universidade Federal do Paraíba, Centro de Ciências Agrárias, Departamento de Zootecnia, Areia, Paraíba, Brasil.

${ }^{4}$ Universidade Federal do Piauí, Centro de Ciências Agrárias, Departamento de Zootecnia, Teresina, Piauí, Brasil.

*Endereço para correspondência: natanaelpss@ @otmail.com.
}

\section{RESUMO}

Objetivou-se estudar efeitos ambientais e genéticos sobre cabras mestiças, exploradas para a produção leiteira. Foram estimados componentes de covariância e parâmetros genéticos das características: idade ao primeiro parto; intervalo de partos e produção de leite em análise uni e multicaracterística, mediante a estatística Bayesiana sob modelo animal. As análises genéticas foram realizadas com cadeias de 1.000 .000 de ciclos. Considerou-se o burn-in dos 100.000 valores iniciais, tomados a cada 300 ciclos, para se obter a distribuição a posteriori com 3.000 amostras. As médias obtidas para idade ao primeiro parto, intervalo de partos e produção de leite foram 581,68 \pm 79,$44 ; 322,89 \pm 132,02$ dias e 226,99 \pm $89,72 \mathrm{~kg}$ de leite, respectivamente. Todos os efeitos incluídos no modelo foram significativos, exceto o tipo de nascimento para o intervalo de partos e produção de leite. As herdabilidades, em análise unicaracterística, foram 0,$14 ; 0,05$ e 0,10 para idade ao primeiro parto, intervalo de partos e produção de leite, respectivamente. $\mathrm{Na}$ mesma ordem, em análise multicaracterística, as herdabilidades foram de 0,$16 ; 0,06$ e 0,11. As estimativas de repetibilidade, para as características intervalo de partos e produção de leite, foram 0,10 e 0,20 respectivamente. As características estudadas mostraram-se fortemente influenciadas pelo ambiente. Os valores da repetibilidade indicam a necessidade de se tomar mais medidas antes da decisão de manter ou descartar o animal. As análises multicaracterísticas levaram a estimativas ligeiramente maiores de herdabilidade.

Palavras-chave: caprinos, componentes de variância, inferência Bayesiana, parâmetros genéticos.

\section{SUMMARY}

This study aimed to evaluate the use of mineral and mineral protein supplement in finishing phase Nellore, grazing Brachiaria brizantha during the rainy season, and its implications for forage intake, animal performance and nutrient digestibility. The fieldwork was located in an area of 26 ha, divided into four paddocks of approximately 6.5 hectares (ha), formed with Brachiaria brizantha Marandu. We used 18 Nellore with 28 months live weight of $400.5 \pm$ $7.5 \mathrm{~kg}$ and castrated in two treatments: mineral supplementation until the termination, and 
mineral supplementation of low protein intake to termination. There was no effect on the consumption of pasture, neutral detergent fiber, crude protein, ether extract, non-fiber carbohydrates, ash and total digestible nutrients. The animal performance and feed conversion were not affected by supplementation. There was no effect on the coefficient of digestibility of dry matter, organic matter, crude protein, ether extract and neutral detergent fiber. There was an effect of protein salt supplementation on the digestibility of non-fiber carbohydrates. In the rainy season the utilization of mineral salt allows the use of animals in pastures.

Keywords: goats, bayesian inference, genetic parameters, variance components.

\section{INTRODUÇÃO}

A avaliação da mudança genética que ocorre nos rebanhos mostra-se importante para mensurar o grau de eficiência do processo de seleção usado, tanto com base em uma, ou, em várias características de interesse. Com a avaliação, é possível verificar se está em processo o melhoramento genético no rebanho, e se a taxa de ganho se apresenta satisfatória. Caso a resposta à seleção não seja favorável, é preciso identificar as falhas e estabelecer métodos mais eficientes que, certamente, terão por base parâmetros genéticos estimados com qualidade.

O estudo de características reprodutivas, por modelos multicaracterísticas, pode ser mais consistente, quando comparado ao uso de modelos unicaracterística, pois considera as relações entre as características. Em análises multicaracterísticas, a avaliação do animal para uma característica se faz pela contribuição de todas as outras envolvidas na análise (LASSEN, 2007). Do ponto de vista do melhoramento genético, as estimativas de parâmetros, obtidas por métodos apropriados, são essenciais, pois acurá-las com o menor erro possível é requerido para o estabelecimento de eficientes programas de seleção. Assim, os Métodos de Monte Carlo via Cadeias de Markov (MCMC), dentre os quais se destaca a amostragem de Gibbs, podem ser utilizados como ferramenta que propicia a inferência Bayesiana. A partir desta são obtidas as estimativas dos componentes de variância e parâmetros genéticos, o que permite a incorporação de informações passadas (a priori), caso existam, a enriquecer o processo de inferência (FARIA et al., 2007).

A amostragem de Gibbs tem sido empregada na estimação de parâmetros genéticos, em estudos que utilizam diferentes modelos, principalmente, para características com poucos dados amostrais (CARNEIRO JÚNIOR et al., 2005; FALCÃO et al., 2009).Dessa forma, objetivou-se avaliar os aspectos ambientais e estimar os componentes de covariância e parâmetros genéticos de características reprodutivas (idade ao primeiro parto e intervalo de partos) e produtiva (produção de leite) em caprinos, por meio da amostragem de Gibbs, sob modelos uni e multicaracterísticas.

\section{MATERIAL E MÉTODOS}

O trabalho foi realizado com dados do rebanho caprino da Fazenda Carnaúba, pertencente à Agropecuária Manoel Dantas Ltda. (AMDA), situada no município de Taperoá, microrregião do Cariri Ocidental da Paraíba. Os registros de idade, ao primeiro parto (IPP), intervalo de partos (IP) e produção total de leite (PL) foram obtidos a partir do controle reprodutivo e produtivo das cabras mestiças, oriundas do cruzamento de reprodutores da raça Pardo Alpino, com fêmeas do tipo 
naturalizado Gurgueia, coletados com representatividade durante 8 (oito) anos consecutivos.

Os animais foram criados em sistema semi-intensivo, alimentados com capimbuffel (Cenchrus ciliaris L.) e vegetação nativa durante a estação chuvosa. Foram fornecidos capim-elefante (Pennisetum purpureum schum.), palma forrageira (Opuntia sp.), raspa de mandioca (Manihot sativa), bagaço de cana hidrolisado (Sacharum oficcinarum) e concentrado proteico, na estação seca, além de sal mineral à vontade no aprisco.

A detecção do cio foi realizada, visualmente, pela manhã e à tarde. Depois de haver a identificação de cio, a cabra era levada à baia do reprodutor correspondente, onde ocorria a cobertura e, em seguida, retornava ao lote. A monta era do tipo natural controlada, sem estação de monta definida. Após a primeira parição, as cabras eram incorporadas no lote dos animais adultos. A ordenha dos animais foi realizada manualmente todos os dias no turno da manhã.

$\mathrm{Na}$ análise dos dados, foram considerados grupos de contemporâneos
(GC) distintos para as características. Os grupos de contemporâneos para característica IPP (GC1) contemplavam animais que pariram no mesmo ano (1 a 8) e mesma estação ( 1 e 2), nos quais a estação 1 corresponde ao período com maior concentração chuvosa, de fevereiro a junho, e a estação 2, ao período com menor concentração chuvosa, de julho a dezembro e no mês de janeiro do mesmo ano. Para as características IP e PL, os grupos de contemporâneos compreendiam animais que pariram no mesmo ano (1 a 8), mesma estação (1 e 2), além da mesma ordem de parição ( 1 a 7 ) e do tipo de nascimento da cria (1 para simples e 2 para múltiplo).

Para gerar o arquivo utilizado nas análises, partiu-se de um banco de dados com 1.939 registros nos quais foram impostas restrições. Assim, permaneceram no arquivo, apenas, cabras com pai e mãe conhecidos, que apresentavam no máximo sete parições, bem como grupos de contemporâneos com no mínimo 3 animais, de modo a restar 532 registros para as análises (Tabela 1).

Tabela 1. Estatística descritiva dos dados para as análises

\begin{tabular}{lccccccc}
\hline Característica & $\mathrm{N}$ & Média & DP & CV $(\%)$ & Mínimo & Máximo & GC \\
\hline IPP (dias) & 392 & 581,68 & 79,44 & 13,66 & 378,00 & 890,00 & 16 \\
IP (dias) & 532 & 322,89 & 132,02 & 40,89 & 124,00 & 828,00 & 78 \\
PL (kg) & 324 & 226,99 & 89,72 & 39,53 & 90,00 & 563,00 & 69 \\
\hline
\end{tabular}

IPP = idade ao primeiro parto; IP $=$ intervalo de partos; $\mathrm{PL}=$ produção de leite; $\mathrm{n}=$ número de observações; $\mathrm{DP}=$ desvio padrão; $\mathrm{CV}=$ coeficiente de variação; $\mathrm{GC}=$ número de grupos de contemporâneos.

Após a edição dos dados e, a partir das fichas de produção e reprodução do rebanho, editou-se um arquivo que continha o número da cabra, pai e mãe, data de nascimento, datas dos partos, datas das coberturas, pesos antes e durante a gestação, ordem e intervalo de partos, número de cabritos nascidos por parto, idade aos partos e produção de leite, bem como os grupos de 
contemporâneos. Para formação dos arquivos de dados e de pedigree, análise de consistência dos dados e a verificação dos efeitos ambientais capazes de influenciar as características IPP, IP e PL, foram utilizados os procedimentos MEANS e GLM do programa Statistical Analysis Systems, versão 9.2 (SAS INSTITUTE, 2003).

Para análise dos efeitos ambientais que podem influenciar as características, foram utilizados dois modelos estatísticos distintos. O modelo 1 foi utilizado para análise da IPP, e o modelo 2 foi utilizado para IP e PL, como seguem:

Modelo 1:

$Y_{i j k l m}=\mu+A_{i}+E_{j}+N_{k}+\varepsilon_{i j k m}$,

Modelo 2:

$Y_{i j k l m n}=\mu+A_{i}+E_{j}+N_{k}+O_{m}+\varepsilon_{i j k m n}$

em que, $y$ é a resposta do animal de acordo com a característica avaliada (IPP, IP e PL); $\mu$ é a média geral da característica; $A_{i}$ é o efeito do ano de parição; $E_{j}$ é o efeito da estação de parição; $N_{k}$ é o efeito do tipo de nascimento; $O_{m}$ é o efeito da ordem de parição; e $\varepsilon$ é o erro aleatório independente, distribuído com média zero e variância $\sigma^{2}$.

Os componentes de covariância e parâmetros genéticos, para fins de comparação, mediante análises Bayesiana uni e multicaracterística, sob modelo animal, foram estimados por meio do aplicativo MTGSAM (Multiple Trait Gibbs Sampler for Animal Models), desenvolvido por Van Tassell \& Van Vleck (1995). Na modelagem, considerou-se a idade do animal, ao parto, como covariável com efeito

$$
\begin{gathered}
y\left|b, a, c, \sigma_{e}^{2} \sim N\left(X b+Z a+W c+I \sigma_{e}^{2}\right) ; a\right| \sigma_{a}^{2} \sim N\left(0, A \sigma_{a}^{2}\right) ; c \mid \sigma_{c}^{2} \sim N\left(0, I \sigma_{c}^{2}\right) ; \\
e \mid \sigma_{e}^{2} \sim N\left(0, I \sigma_{e}^{2}\right),
\end{gathered}
$$

quadrático para as características IP e PL. Consideraram-se os grupos de contemporâneos como efeito fixo, de acordo com a solicitação do programa. Entretanto, na análise Bayesiana os efeitos fixos e aleatórios inclusos no modelo são considerados variáveis aleatórias.

Foram utilizados dois modelos diferentes nas análises, o primeiro sem conter o efeito de ambiente permanente para avaliação da característica IPP, e segundo modelo contemplava esse efeito para as características IP e PL. Dessa forma, os modelos animais em notação matricial podem ser representados assim:

Modelo 1: $y=X b+Z a+e$,

Modelo 2: $y=X b+Z a+W c+e$,

em que $y$ é o vetor das observações da característica medida nos animais (IPP, IP e PL); $b$ é o vetor de efeitos "fixos"; $a$ é o vetor de efeitos aleatórios que representa os valores genéticos aditivos diretos de cada animal; $c$ é o vetor de efeitos de ambiente permanente (não correlacionado) para as características IP e PL; $e$ é o vetor de erros aleatórios; $X, Z$ e $W$ são matrizes de incidência que relacionam as observações aos efeitos fixos e aos efeitos aleatórios aditivo direto e de ambiente permanente, na respectiva ordem.

Para os modelos adotados, sob o enfoque bayesiano, procederam-se as seguintes pressuposições: em análise unicaracterística, assume-se que a distribuição condicional dos dados $(y)$, dados, $b, a, c$ e $\sigma_{e}^{2}$ é normal e multivariada, assim: 
em que $\sigma_{a}^{2}, \sigma_{c}^{2}$ e $\sigma_{e}^{2}$ são componentes de variância genético aditivo direto, de ambiente permanente e residual, respectivamente; $A$ é matriz de numeradores do coeficiente de parentesco de Wrigth, e $I$ é matriz identidade de ordem igual ao número de animais com observações. Usualmente, $b$ assume priori não informativa, pois, dentro do contexto Bayesiano, não há distinção entre efeitos fixos e aleatórios. Dessa forma: $P(b) \alpha$ constante.

Em análise multicaracterística, o modelo completo em notação matricial é dado como segue:

$$
\left[\begin{array}{l}
y_{1} \\
y_{2}
\end{array}\right]=\left[\begin{array}{ll}
X_{1} & 0 \\
o & X_{2}
\end{array}\right]\left[\begin{array}{l}
b_{1} \\
b_{2}
\end{array}\right]+\left[\begin{array}{ll}
Z_{1} & 0 \\
0 & Z_{2}
\end{array}\right]\left[\begin{array}{l}
a_{1} \\
a_{2}
\end{array}\right]+\left[\begin{array}{ll}
W_{1} & 0 \\
0 & W_{2}
\end{array}\right]\left[\begin{array}{l}
c_{1} \\
c_{2}
\end{array}\right]+\left[\begin{array}{l}
e_{1} \\
e_{2}
\end{array}\right],
$$

Pressupõe-se $y \mid b, a, c, \sigma_{e}^{2} \sim N M V(X b+Z a+W c, R)$, com $R=\operatorname{diag}\left\{\sigma_{e}^{2}\right\}$, seja a função de verossimilhança.

As pressuposições acerca das distribuições a priori para os parâmetros desconhecidos são consideradas como a seguir:

$a \mid G_{0} \sim \operatorname{NMV}(0, G) \quad$ com $\quad G=A \otimes G_{0}$, em que $A$ é a matriz de parentesco entre os animais, e $G_{0}$ é a matriz de covariância genética aditiva entre as características;

$c \mid C_{0} \sim N M V(0, C), \quad$ com $C=I \otimes C_{0}$, em que I é uma matriz identidade, e $C_{0}$ é a matriz de covariância de ambiente permanente;

$G_{0} \mid v_{a}, S_{a}^{2} \sim W^{-1}\left(v_{a}, v_{a}, S_{a}^{2}\right) ;$

$C_{0} \mid v_{c}, S_{c}^{2} \sim W^{-1}\left(v_{c}, v_{c}, S_{c}^{2}\right), \quad$ em que $v_{a}, S_{a}^{2}$ e $v_{c}, S_{c}^{2}$ representam o grau de confiança e os valores a priori para as covariâncias genética aditiva e de ambiente permanente, respectivamente; $\sigma_{e}^{2} \mid v_{e}, S_{e}^{2} \sim \chi^{-2}\left(v_{e},\left[v_{e} S\right]_{e}^{2}\right)$ em que $v_{e}, S_{e}^{2}$ representam o grau de confiança e os valores a priori para do resíduo;

$b \alpha$ constante; $\mathrm{e}$

$N M V, W^{-1} \quad$ e $\quad \chi^{-2} \quad$ refere-se às distribuições normal multivariada, Wishart invertida e Qui-quadrado invertida, respectivamente e $\otimes=$ operador produto-direto.

$\mathrm{O}$ grau de liberdade, correspondente à distribuição Wishart Invertida, que indica o grau de confiabilidade da distribuição inicial $(v)$, foi nulo (flat) para todas as variâncias iniciais, ou seja, não refletiu grau de conhecimento sobre os parâmetros $(v=0)$. Foram realizadas análises com cadeias de 1 milhão de ciclos. Considerou-se o burn-in dos 100 mil valores iniciais. Para evitar a redundância das informações, causada pelas correlações seriais entre os valores gerados subsequentemente, foram tomadas amostras a cada 300 ciclos (Intervalos de amostragem - Thinning interval), para se obter a distribuição a posteriori.

Dessa forma, foram utilizadas distribuições a posteriori com 3.000 amostras. A dimensão de burn-in e intervalo de amostragem foram obtidos por análise prévia das cadeias geradas pelo amostrador de Gibbs através do programa Gibanal, com sistema operacional DOS, desenvolvido por Van Kaam (1998) para a monitoração da convergência.

O erro de Monte Carlo foi obtido mediante o cálculo da variância das amostras, retiradas para cada componente, dividida pelo número de amostras. Assim, a raiz quadrada desse valor se refere à aproximação do 
desvio-padrão do erro associado ao tamanho da cadeia de Gibbs (VAN TASSELL \& VAN VLECK, 1995).

\section{RESULTADOS E DISCUSSÃO}

As médias obtidas para idade ao primeiro parto (IPP), intervalo de partos (IP) e produção de leite (PL) foram $581,68 \pm 79,44$ dias; $322,89 \pm 132,02$ dias e $226,99 \pm 89,72 \mathrm{~kg}$ de leite, respectivamente. Valores superiores a esses foram obtidos por Lôbo e Silva (2005), ao avaliarem caprinos das raças Saanen e Anglonubiana. Gonçalves et al. (2008) observaram médias de 365 dias para IPP e IP e média de $708 \mathrm{~kg}$ para a PL em cabras da raça Saanen. Torres-Vázquez et al. (2009) observaram valores de idades ao primeiro parto em torno de 490 dias em animais da raça Saanen criados no México.

O valor médio da idade, ao primeiro parto, pode ser considerado elevado (581,68 $\pm 79,44$ dias), em torno de 19 meses. Possivelmente, a IPP tenha sido influenciada pelo manejo à primeira cobertura, pois a identificação do cio era realizada somente duas vezes ao dia e apenas sob o aspecto visual. Gonçalves et al. (1997ab) relataram que, para conseguir resultados econômicos razoáveis, as cabritas devem alcançar o primeiro parto com 12 meses, independente do fotoperiodismo, porém, para criação intensiva no sudeste do país.

Vale ressaltar que precocidade ao primeiro parto e a redução do intervalo de partos são importantes do ponto de vista reprodutivo, pois os animais mostram sua eficiência em desenvolvimento por consequência do bom manejo na fase de crescimento. Isso gera coberturas e partos precoces com aproveitamento pleno do animal na sua vida útil.

Todos os efeitos descritos no modelo foram significativos $(\mathrm{P}<0,05)$, com exceção do tipo de nascimento das crias para IP e PL. A influência dos fatores ano e estação de parição explica-se como decorrente de flutuações do clima, especificamente. A variação de pluviosidade entre e dentro dos anos estudados causam oscilações no desempenho, em decorrência da estacionalidade na disponibilidade de alimentos, em termos qualitativos e quantitativos, ainda que o rebanho seja submetido a manejo alimentar que visa contornar problemas de entressafra. Resultados similares aos aqui obtidos foram relatados por Sarmento et al. (2003), Pimenta Filho et al., (2004), Torres-Vázquez et al. (2009) e Montaldo et al. (2010). Tais autores afirmaram ocorrer forte influência desses fatores em características reprodutivas e produtivas.

A não significância do tipo de nascimento sobre as características IP e PL pode ser atribuída ao manejo dos cabritos, aleitados artificialmente. $\mathrm{Ou}$ seja, a cabra, ao receber estímulo de um cabrito, é diferente do estímulo de dois ou três, o que aumentaria a demanda de nutrientes por parte da gestação e para a síntese do leite, de modo a garantir o nascimento e sobrevivência das crias. Com isso, haveria aumento do período de serviço e, consequentemente, do intervalo de partos, pelo fato de a cabra necessitar de maior tempo para se recuperar e retornar à atividade reprodutiva. Como as cabras passam a receber estímulo único depois da parição, mediante o ordenhador, esse efeito seria anulado, a corroborar com os relatos de Sarmento et al. (2003).

No que se refere à estimação de componentes de variância, observou-se que o desvio-padrão do erro de Monte 
Rev. Bras. Saúde Prod. Anim., Salvador, v.13, n.4, p.1084-1098 out./dez., 2012 http://www.rbspa.ufba.br ISSN 15199940

Carlo foi pequeno e praticamente nulo, o que confirma que o tamanho da cadeia amostral utilizada foi suficiente para obtenção de estimativas a posteriori das distribuições marginais dos componentes de covariância. Ou seja, a convergência foi alcançada pela cadeia de Gibbs (Tabela 2).

Tabela 2. Distribuições a posteriori dos componentes de covariância e parâmetros genéticos em análise unicaracterística

\begin{tabular}{|c|c|c|c|c|c|c|c|}
\hline \multirow{2}{*}{ Características } & \multirow{2}{*}{$\begin{array}{l}\text { Componentes e } \\
\text { Parâmetros }\end{array}$} & \multirow{2}{*}{ Média } & \multirow{2}{*}{ Moda } & \multirow{2}{*}{ Mediana } & \multicolumn{2}{|c|}{ IC-95\% } & \multirow{2}{*}{ EMC* } \\
\hline & & & & & LCL & UCL & \\
\hline \multirow{3}{*}{ IPP } & $\sigma_{a}^{2}$ & 2014,19 & 1994,19 & 1921,76 & 1978,84 & 2049,55 & 0,01 \\
\hline & $\sigma_{e}^{2}$ & 12559,96 & 12659,96 & 12456,85 & 12484,51 & 12635,40 & 0,10 \\
\hline & $h^{2}$ & 0,14 & 0,13 & 0,13 & 0,13 & 0,14 & - \\
\hline \multirow{5}{*}{ IP } & $\sigma_{a}^{2}$ & 795,73 & 801,38 & 779,12 & 772,88 & 808,58 & 0,0030 \\
\hline & $\sigma_{c}^{2}$ & 652,49 & 772,11 & 615,34 & 639,06 & 776,91 & 0,0004 \\
\hline & $\sigma_{e}^{2}$ & 14222,86 & 14201,12 & 14154,29 & 14181,69 & 14264,04 & 0,2000 \\
\hline & $h^{2}$ & 0,05 & 0,05 & 0,05 & 0,04 & 0,05 & - \\
\hline & $t$ & 0,09 & 0,09 & 0,08 & 0,09 & 0,10 & - \\
\hline \multirow{5}{*}{ PL } & $\sigma_{a}^{2}$ & 729,42 & 719,61 & 720,04 & 717,60 & 767,24 & 0,0030 \\
\hline & $\sigma_{c}^{2}$ & 641,11 & 629,82 & 648,55 & 629,80 & 652,43 & 0,0002 \\
\hline & $\sigma_{e}^{2}$ & 5524,09 & 5531,09 & 5498,42 & 5501,09 & 5547,09 & 0,0900 \\
\hline & $h^{2}$ & 0,11 & 0,10 & 0,10 & 0,10 & 0,11 & - \\
\hline & $t$ & 0,20 & 0,19 & 0,19 & 0,19 & 0,20 & - \\
\hline
\end{tabular}

IPP = idade ao primeiro parto; IP = intervalo de partos; PL - produção de leite; $\sigma_{a}{ }^{2}=$ variância devido aos efeitos genéticos aditivos direto; $\sigma_{c}{ }^{2}=$ variância devido aos efeitos de ambiente permanente (não correlacionados); $\sigma_{e}{ }^{2}=$ variância residual; $h^{2}=$ herdabilidade da característica; $t$ = repetibilidade da característica; IC = intervalo de credibilidade a $95 \%$; LCL = Limite de credibilidade inferior; UCL = Limite de credibilidade superior; $\mathrm{EMC}^{*}=$ erro de Monte Carlo, com base na estimativa média das variâncias.

Com relação ao erro de Monte Carlo, Van Tassel \& Van Vleck (1995) afirmam que é considerado pequeno, quando seu valor somado à estimativa média da distribuição a posteriori dos coeficientes de herdabilidade, o que não altera o valor dessa estimativa, se considerado até a segunda casa decimal. Além disso, pela análise gráfica da convergência, observou-se a estabilização do processo iterativo
(Figura 1). Dessa maneira, pode-se acreditar que as estimativas dos parâmetros são as médias das distribuições a posteriori, pois a condição de distribuição estacionária foi atingida.

Em virtude da distribuição a posteriori das estimativas obtidas possuir densidade simétrica (Figura 2), os valores da média e da moda resumem a medida da distribuição. Ou seja, quando 
Rev. Bras. Saúde Prod. Anim., Salvador, v.13, n.4, p.1084-1098 out./dez., 2012 http://www.rbspa.ufba.br ISSN 15199940

uma distribuição a posteriori apresenta valores de médias, medianas e modas próximos entre si, significa que esta distribuição se assemelha a uma curva normal.

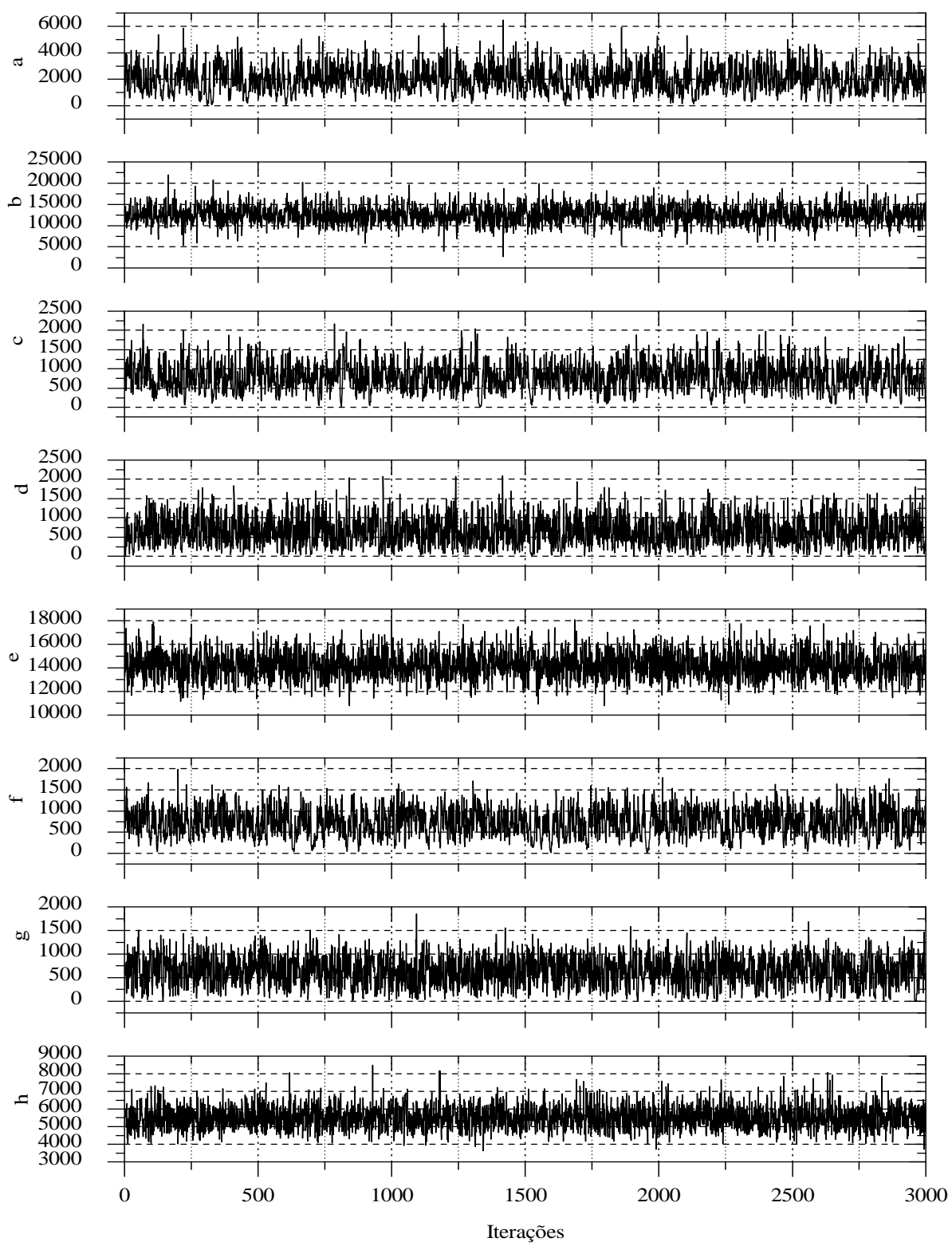

Figura 1. Processo da amostragem de Gibbs da variância genética aditiva (a) e variância residual (b) da característica IPP e variância aditiva (c e f), variância de ambiente permanente (d e g) e variância residual $(e \mathrm{e} \mathrm{h})$ das características IP e PL, respectivamente, em função do número de interações da distribuição a posteriori. 
Rev. Bras. Saúde Prod. Anim., Salvador, v.13, n.4, p.1084-1098 out./dez., 2012 http://www.rbspa.ufba.br ISSN 15199940

a
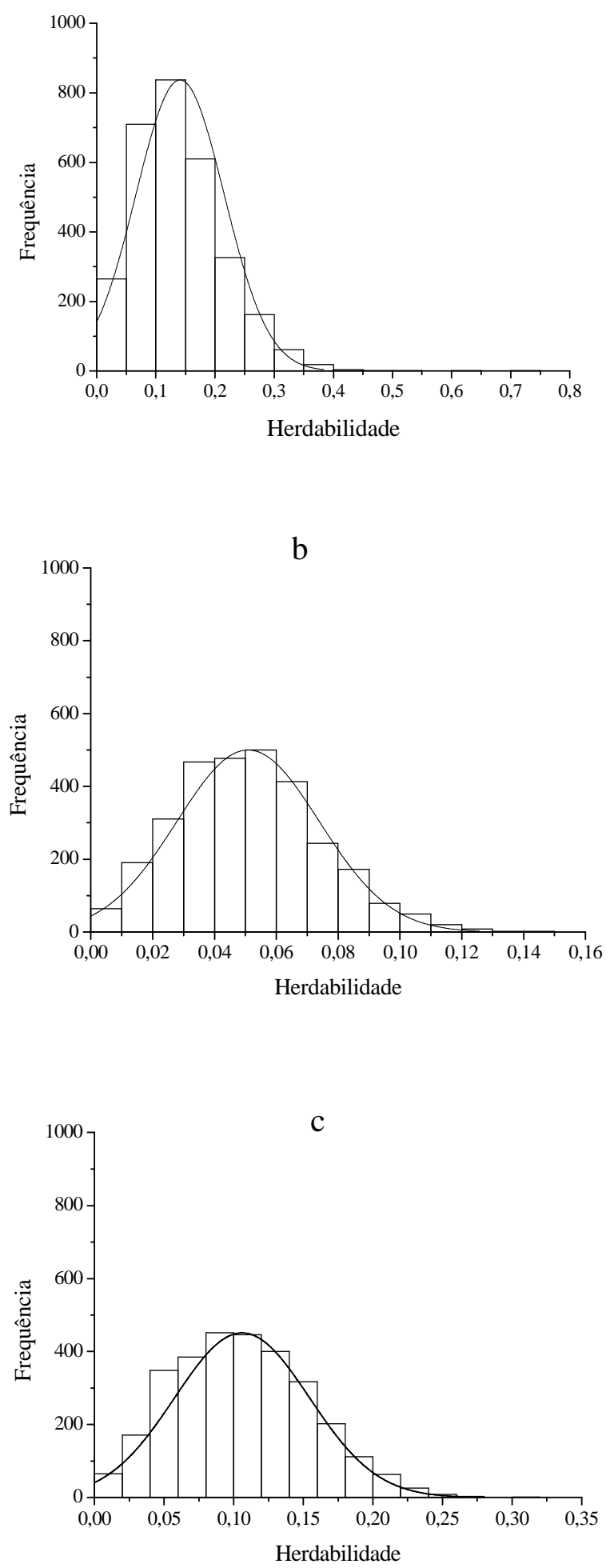

Figura 2. Histogramas da distribuição a posteriori das estimativas de herdabilidade para Idade ao Primeiro parto (a), Intervalo de Partos (b) e Produção de leite (c) em caprinos mestiços. 
Segundo Wright et al. (2000), a moda é a mais aconselhável medida de posição das distribuições a posteriori, pois aponta o valor de maior frequência. A esse respeito, é possível observar que a moda e a média da herdabilidade das características são praticamente iguais o que, possivelmente, foi causado pelo fato de os valores da moda dos componentes de variância estarem dentro do intervalo de credibilidade.

As estimativas dos componentes de variância e parâmetros genéticos obtidos pela amostragem de Gibbs também permitiram a obtenção imediata de intervalos de credibilidade (Tabela 2), sem deixar de considerar a incerteza existente nos parâmetros simultaneamente, portanto, seria mais um indicador de precisão do método Bayesiano (GELMAN et al., 1997). A partir das estimativas dos componentes de covariância das características estudadas (Tabela 2 e 3 ), estimaram-se os parâmetros genéticos, herdabilidade, repetibilidade com o modelo unicaracterística e as correlações genéticas com o modelo multicaracterística.

De maneira geral, as estimativas de variância genética foram abaixo das relatadas na literatura (SARMENTO et al., 2003; PIMENTA FILHO et al., 2004; LÔBO \& SILVA, 2005), exceto para IPP. A estimativa desses componentes mostrase importante para o conhecimento da estrutura da população e o delineamento de estratégias de seleção adequadas, inclusive para utilização na estimativa de índices de seleção.

Destaca-se que as estimativas de variância genética aditiva nas análises multicaracterística foram superiores às estimadas em análises unicaracterísticas, principalmente, para IPP e IP. Esse aumento na diferença do componente de variância genético aditivo no modelo reflete a remoção do vício, decorrente da seleção e ao maior número de informações. Além disso, reflete as relações entre as características, o que possibilitou resgatar parte da variância aditiva direta e levour a estimativas maiores de herdabilidade (SARMENTO et al., 2006).

Mesmo com o aumento no valor da estimativa de variância genética aditiva, na análise multicaracterística, com redução expressiva na variância residual, a variância fenotípica estimada foi, praticamente, a mesma nas duas análises. Dessa forma, o aumento do número de informações nas análises conjuntas, com uso das relações entre os animais nos diferentes níveis de variabilidade, permitiram filtrar maiores proporções de variância genética aditiva que, antes, eram adicionadas ao componente residual. Ou seja, a utilização de componentes de covariância entre as variáveis possibilitou a obtenção de estimativas de variância mais apuradas, o que diminuiu o componente da variância residual a favor dos componentes de variância genéticos aditivos.

A decisão quanto a utilizar modelos multicaracterísticas, ao invés de unicaracterística irá depender, principalmente, das herdabilidades $\mathrm{e}$ correlações entre as características, pois conforme a combinação entre tais parâmetros, a eficiência entre esses dois modelos pode ser semelhante (BALDI et al., 2010).Em análise unicaracterística obtiveram-se valores de herdabilidade de 0,14; 0,05 e 0,10 para IPP, IP e PL, respectivamente. Na mesma ordem, para análise bicaracterística, as herdabilidades foram de 0,16; 0,06 e 0,11. Dessa forma, é fácil observar que houve sensível melhora nas estimativas e incremento nos componentes de variância. $\mathrm{O}$ aumento nas estimativas de herdabilidade com modelos multicaracterísticas também foi relatado por Sarmento et al. (2006). 
Tabela 3. Médias a posteriori para os componentes de covariância e parâmetros genéticos em análise multicaracterística

\begin{tabular}{|c|c|c|c|c|c|c|c|c|c|c|c|c|c|c|}
\hline \multirow{3}{*}{ Características } & \multicolumn{13}{|c|}{ Componentes de covariância e parâmetros genéticos } & \multirow{3}{*}{$\mathrm{EMC}^{*}$} \\
\hline & \multirow{2}{*}{$\sigma_{a}^{2}$} & \multirow{2}{*}{$\sigma_{a_{x, y}}$} & \multirow{2}{*}{$\sigma_{c}^{2}$} & \multirow{2}{*}{$\sigma_{c x, y}$} & \multirow{2}{*}{$\sigma_{e}^{2}$} & \multirow{2}{*}{$\sigma_{e x, y}$} & \multirow{2}{*}{$h^{2}$} & \multicolumn{2}{|c|}{ IC-95\% } & \multirow{2}{*}{$r_{x, y}$} & \multirow{2}{*}{$t$} & \multicolumn{2}{|c|}{$\mathrm{IC}-95 \%$} & \\
\hline & & & & & & & & $\mathrm{LCL}$ & $\mathrm{UCL}$ & & & $\mathrm{LCL}$ & $\mathrm{UCL}$ & \\
\hline IPP & 2365,89 & \multirow[b]{2}{*}{788,92} & - & \multirow[b]{2}{*}{-} & 12450,82 & \multirow[b]{2}{*}{$-1771,05$} & 0,16 & 0,15 & 0,17 & \multirow[b]{2}{*}{0,52} & - & - & - & 0,001 \\
\hline IP & 965,39 & & 653,39 & & 14170,63 & & 0,06 & 0,04 & 0,06 & & 0,10 & 0,09 & 0,11 & 0,018 \\
\hline IPP & 2420,34 & \multirow[b]{2}{*}{$-231,64$} & & \multirow[b]{2}{*}{-} & 12335,48 & \multirow[b]{2}{*}{479,1} & 0,16 & 0,15 & 0,17 & \multirow[b]{2}{*}{$-0,18$} & & - & - & 0,003 \\
\hline $\mathrm{PL}$ & 737,76 & & 649,95 & & 5522,64 & & 0,11 & 0,10 & 0,12 & & 0,20 & 0,18 & 0,21 & 0,022 \\
\hline IP & 756,09 & \multirow[b]{2}{*}{98,75} & 455,46 & \multirow{2}{*}{$-251,54$} & 14384,94 & & 0,05 & 0,04 & 0,06 & \multirow[b]{2}{*}{$-0,22$} & 0,08 & 0,07 & 0,11 & 0,029 \\
\hline PL & 799,83 & & 1163,75 & & 5385 & 4243,83 & 0,11 & 0,09 & 0,12 & & 0,27 & 0,23 & 0,28 & 0,006 \\
\hline
\end{tabular}

IPP = idade ao primeiro parto; IP = intervalo de partos; $\mathrm{PL}=$ produção de leite; $\sigma_{a}{ }^{2}=$ variância devido aos efeitos genéticos aditivos direto; $\sigma_{a x, y}=$ covariância genética entre a primeira e segunda característica de cada análise; $\sigma_{c}{ }^{2}=$ variância devido aos efeitos de ambiente permanente (não correlacionados); $\sigma_{c x, y}=$ covariância de ambiente permanente entre a primeira e segunda característica de cada análise; $\sigma_{e}{ }^{2}=$ variância residual; $\sigma_{e x, y}=$ covariância residual entre a primeira e segunda característica de cada análise; $h^{2}=$ herdabilidade da característica; $r_{x, y}=$ correlação genética entre a primeira e segunda característica de cada análise; $t=$ repetibilidade da característica. $\mathrm{IC}=$ intervalo de credibilidade a 95\%; LCL $=$ Limite de credibilidade inferior; UCL $=$ Limite de credibilidade superior; EMC $=$ erro de Monte Carlo em função estimativa da variação da herdabilidade média. 
As estimativas de herdabilidades observadas indicam relação baixa entre o fenótipo e genótipo dos indivíduos. Portanto, a seleção de fêmeas pelo fenótipo promoverá lento incremento genético na população. Assim, a partir dos resultados obtidos e pelo fato de as características serem limitadas ao sexo, para os reprodutores, o teste de progênie é o método indicado como o mais eficaz para seleção de bodes destinados à reprodução vislumbrando o incremento da IPP, IP e PL.

A estimativa da herdabilidade para o IP e PL mostram que o fenótipo não é um bom indicador do genótipo dos indivíduos. Resultados similares foram obtidos por Bagnicka et al. (2007). Assim, espera-se que a seleção não proporcione ganhos genéticos satisfatórios.

Mugambi et al. (2007) e Barbosa Neto et al. (2010) recomendam a utilização de cruzamentos, desde que mantenha elevado nível de heterozigose, o que contribuiria para um melhor desempenho de forma mais rápida. Como as herdabilidades estimadas para o IP foram baixas, deve-se ressaltar que a expressão dessa característica pode estar intimamente ligada à PL, o que, por sua vez, pode comprometer a avaliação do verdadeiro potencial reprodutivo dos animais, uma vez que os caprinocultores tendem a aumentar o IP por estenderem a lactação dos animais.

Lôbo \& Silva (2005) obtiveram herdabilidades de 0,49 e 0,$21 ; 0,01$ e 0,06 e 0,10 e 0,12 para IPP, IP e PL com as raças Anglonubiana e Saanen, respectivamente. $\mathrm{Na}$ literatura, é possível observar variações nas estimativas para os parâmetros genéticos em estudo, possivelmente, pela pouca informação utilizada nas análises. Vale ressaltar que a estimativa desses parâmetros foi realizada pelo método da máxima verossimilhança restrita (REML). Garcia-Peniche et al. (2012), ao estudarem algumas raças caprinas, obtiveram herdabilidades que variavam entre 0,16 a 0,41 para idade ao primeiro parto; 0,02 a 0,21 para intervalo de partos; e de 0,36 e 0,61 para produção de leite. Fica evidente que a herdabilidade varia entre raças, famílias, populações e pode ser influenciada pelo ambiente.

Observou-se que a correlação genética estimada entre IPP e IP foi positiva e moderada. Esse fato pode ter ocorrido em virtude de a criação voltar-se à produção de leite, pois animais precoces tendem a ser reprodutivamente superiores. Daí, resulta que, ao apresentarem primeiro parto precocemente, esses animais tenderão a apresentar menores intervalos de parto. No entanto, sabe-se que a resposta correlacionada não depende exclusivamente da correlação genética entre as características, mas também das herdabilidades das características envolvidas no processo de seleção.

Dessa forma, apesar da moderada correlação genética entre as características IPP e IP, a resposta correlacionada pela seleção indireta, mesmo eficiente, poderá resultar em ganhos genéticos baixos. Ao utilizarem metodologia de análise REML com modelo multivariado para estimação de parâmetros genéticos em caprinos de várias raças, Montaldo et al. (2010) relataram resultados similares aos desta pesquisa para a raça Saanen. Destaca-se que a característica intervalo de parto apresentou herdabilidade baixa $(0,02-$ $0,15)$, a corroborar com os resultados obtidos.

As estimativas de repetibilidade para as características IP e PL apresentaram-se, de forma geral, com baixa magnitude (Tabela 3), de modo que serão necessárias mais mensurações nos 
animais para representar sua real capacidade de produção. Ou seja, uma única observação feita no indivíduo apresenta pequeno valor para a sua seleção, por isso é necessário que novas ocorrências sejam consideradas. Destaca-se que, com o aumento de mensurações nos animais, podem-se minimizar os possíveis erros decorrentes da coleta dos dados. Estimativas de repetibilidade inferiores para essas características foram relatadas por Lôbo \& Silva (2005) e superiores foram registradas por Pimenta Filho et al. (2004) e GarciaPeniche et al. (2012).

As características que se repetem ao longo da vida do animal, a exemplo do IP e da PL, se expressam em diferentes intensidades em cada ocorrência, e o coeficiente de repetibilidade estimado em 0,10 e 0,20 , respectivamente, representa a correlação entre os desempenhos sucessivos dos animais. Apesar de baixo, esse coeficiente mostra-se como importante ferramenta, quando se trabalha com animais que apresentam várias medidas da mesma característica, o que pode auxiliar a predição de desempenhos futuros dos animais.

Contudo, destaca-se que a seleção para menor idade, ao primeiro parto, favorece a eficiência reprodutiva com a diminuição do intervalo de partos. Entretanto, a precocidade, ao primeiro parto, pode interferir na expressão do potencial produtivo com a diminuição da produção de leite. Assim, as análises multicaracterísticas possibilitaram $\mathrm{O}$ resgate de parte da variância aditiva direta e a obtenção de estimativas de herdabilidade superiores às alcançadas em análise unicaracterística.

\section{REFERÊNCIAS}

BAGNICKA, E.; WALLIN, E.; LUKASZEWICZ, M.; ADNOY, T. Heritability for reproduction traits in Polish and Norwegian populations of dairy goat. Small Ruminant Research, v.68, p.256-262, 2007.

BALDI, F.; ALENCAR, M.M.; ALBUQUERQUE, L.G. Estimativas de parâmetros genéticos para características de crescimento em bovinos da raça Canchin utilizando modelos de dimensão finita. Revista Brasileira de Zootecnia, v.39, n.11, p.2409-2417, 2010.

BARBOSA NETO, A.C.; OLIVEIRA, S.M.P.; FACÓ, O.; LÔBO, R.N.B. Efeitos aditivos e não-aditivos em características de crescimento, reprodutivas e habilidade materna em ovinos das raças Santa Inês, Somalis Brasileira, Doper e Poll Dorset. Revista Brasileira de Zootecnia, v.39, n.9, p.1943-1951, 2010.

CARNEIRO JÚNIOR, J.M.; ASSIS, G.M.L.; EUCLYDES, R.F.; LOPES, P.S. Influência da informação a priori na avaliação genética animal utilizando dados simulados. Revista Brasileira de Zootecnia, v.34, n.6, p.1905-1913, 2005.

FALCÃO, A.J.S.; MARTINS, E.N.; COSTA, C.N.; MAZUCHELI, J..

Efeitos do número de animais na matriz de parentesco sobre estimativas de componentes de variância para produção de leite usando os métodos de Máxima Verossimilhança Restrita e Bayesiano. Revista Brasileira de Zootecnia, v.38, n.8, p.1478-1487, 2009. 
Rev. Bras. Saúde Prod. Anim., Salvador, v.13, n.4, p.1084-1098 out./dez., 2012 http://www.rbspa.ufba.br ISSN 15199940

FARIA, C.U.; MAGNABOSCO, C.U.; LOS-REYES, A.; LÔBO, R.B.; BEZERRA, L.A.F. Inferência Bayesiana e sua aplicação na avaliação genética de bovinos da raça Nelore: revisão bibliográfica. Ciência Animal Brasileira, v.8, p.75-86, 2007.

GARCIA-PENICHE, T.B.; MONTALTO, H.H.; VALENCIAPOSADAS, M.; WIGGANS, G.R.; HUBBARD, S.M.; TORRESVÁZQUEZ, J.A.; SHEPARD, L. Breed differences over time and heritability estimates for production and reproduction traits os dairy goats in the United States, Journal of Dairy Science, v.95, p.2707-2717, 2012.

GELMAN, A.; CARLIN, J.B.; STERN, H.S. RUBIN, D.B. Bayesian data analysis. London: Chapman Hall, 1997. 526p.

GONÇALVES, A.L.; LANA, R.P.; VIEIRA, R.A.M. Avaliação se sistemas de produção de caprinos leiteiros na região sudeste do Brasil. Revista

Brasileira de Zootecnia, v.37, n.2, p.366-376, 2008.

GONÇALVES, H.C.; SILVA, M.A.; RAMOS, A.A.; ESPESCHIT, J.B.; WECHSLER, F. S. Fatores genéticos e de meio no intervalo de partos de caprinos leiteiros. Revista Brasileira de Zootecnia, v.26, n.5, p. 905-913, 1997a.

GONÇALVES, H.C.; SILVA, M.A; REGAZZI, A.J.; LOPES, P.S.; MARTINS, E.N.; RAMOS, A.A. Fatores genéticos e de meio na idade ao primeiro parto de caprinos leiteiros.

Revista Brasileira de Zootecnia, v.26, n.3, p. 485-493, 1997 b.
LASSEN, J.; SORENSEN, M.K.; MADSEN, P.; DUCROCQ, V. An approximate multitrait model for genetic evaluation in dairy cattle with a robust estimation of genetic trends. Genetics Selection Evolution, v.39, p.353-367, 2007.

LÔBO, R.N.B.; SILVA, F.L.R.

Parâmetros genéticos para características de interesse econômico em cabras da raça Saanen e Anglonubiana. Revista Ciência Agronômica, v.36, n.1, p.104-110, 2005.

MONTALDO, H.H.; VALENCIAPOSADAS.; WIGGANS, G.R.; SHEPARD, L.; TORRES-VÁZQUEZ, J.A. Short communication: genetic and evironmental relationships between Milk yield and kidding interval in dairy goatas. Journal of Dairy Science, v. 93, p.370-372, 2010.

MUGAMBI, J.N.; WAKHUNGU, J.W.; INYANGALA, B.O. Evaluation of the performance of the Kenya goat composites: additive and non-additive genetic parameters. Small Ruminant

Research, v.72, p.149-156, 2007.

PIMENTA FILHO, E.C.; SARMENTO, J.L.R.; RIBEIRO, M.N. Efeitos genéticos e ambientais que afetam a produção de leite e duração da lactação de cabras mestiças no estado da Paraíba. Revista Brasileira de Zootecnia, v.33, n.6, p.1426-1431, 2004.

SAS INSTITUTE. SAS/STAT ${ }^{\circ}$ User's

Guide. Version 9.2. Cary, NC, 2003.

SARMENTO, J.L.R.; PIMENTA FILHO, E.C.; RIBEIRO, M.N.; ARAÚJO, C.V.; BREDA, F.C.; PIRES, A.V.; TORRES FILHO, R.A.; TORRES, R.A. Fatores genéticos e de ambiente sobre o intervalo de partos em cabras leiteiras no semi-árido 
Nordestino. Revista Brasileira de

Zootecnia, v.32, n.4, p.875-879, 2003.

SARMENTO, J.L.R.; TORRES, R.A.; SOUSA, W.H.; PEREIRA, C.S.;

LOPES, P.S.; BREDA, F.C. Estimação de parâmetros genéticos para características de crescimento de ovinos Santa Inês utilizando modelos uni e multicaracterísticas. Arquivo

Brasileiro de Medicina Veterinária e Zootecnia, v.58, n.4, p.581-589, 2006.

TORRES-VÁZQUEZ, J.A.; VALENCIA-POSADAS, M.; CASTILLO-JUÁREZ, H.; MONTALDO, H.H. Genetic and phenotypic parameters of Milk yield, Milk composition and age at first kidding in Saanen goats from Mexico. Livestock Science, v.126, p.147-153, 2009.

VAN KAAM, J.B.C.H.M. Gibanal 2.9: analyzing program for Markov Chain Monte Carlo sequences. Wageningen, Netherlands: Wageningen Agricultural University, 1998.
VAN TASSELL, C. P., VAN VLECK, L. D. A manual for use of MTGSAM: a set of FORTRAN programs to apply Gibbs sampling to animal models for variance component estimation. Lincoln: USDA/ARS, 1995.

WRIGHT, D.R.; STERN, H.S.; BERGER, J. Comparing traditional and Bayesian analyses of selection experiments in animal breeding. Journal of Agricultural Biological and Environmental Statistics, v.5, n.2, p.240-256, 2000.

Data de recebimento: 12/03/2012

Data de aprovação: 27/11/2012 